\title{
Luis de Morales. Influencias indirectas e interrelación de escuelas españolas: nuevas obras
}

\section{Isabel Mateo Gómez}

Profesora de Investigación del CSIC

(Jubilada)

Resumen: Se dan a conocer nuevas obras de Morales sujetas a la interrelación de escuelas españolas y no leonardescas.

Palabras clave: Morales; Interrelación de escuelas artísticas españolas; Manierismo a través de otros pintores, grabados, iconografía.

Abstract: Three hitherto unseen works from Morales are released. They belong to different periods which are not influenced by Leonardo. In these works, we can notice the interrelations of Spanish artistic schools and of pictures.

Key words: Morales; Interrelation of peninsular schools; Mannerism through other Spanish painters, engravings, iconography.

Recibido: 22/03/2017

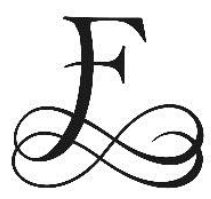

ernando Marías denominó, acertadamente, nuestra pintura renacentista como "El largo siglo XVI". En la segunda mitad de esta centuria, fueron escasos los pintores españoles que salieron de nuestro país, para formarse en Italia. Sin embargo, fueron un mayor número los extranjeros que vinieron a establecerse aquí, bien sumándose a las escuelas peninsulares, ya establecidas, o creándolas. La mayoría de estos últimos eran de origen flamenco, pero con anterior estancia en Italia. También hay que resaltar el gran número de obras que se importaron de Italia y Flandes para decorar palacios y cubrir curiosidades de la nobleza y de la iglesia, amén de las "estampas" que, como en periodos anteriores, servían de inspiración a nuestros artistas, en un peculiar ejercicio didáctico. A todo ello denominó Elías Tormo "influencias indirectas de 
segunda mano"1. Entre las escuelas más importantes, en esta segunda mitad del siglo XVI, se hallan Valladolid, donde Alonso Berruguete, al volver de Italia, creó escuela e influyó en su ámbito próximo; Toledo, que adquiere gran importancia por la presencia de un gran pintor local, Juan Correa de Vivar, que camina a través de influencias indirectas; Pedro Machuca, con su aprovechada estancia en Italia, y varios flamencos que, desde la vecina península, se establecen en Toledo: Cornelio Cyaneus e Isaac de Helle. En el primero encontraremos conexiones con Morales. La escuela valenciana, en sus comienzos, gozó con la presencia de Pablo de San Leocadio y de los Hernandos, vinculados a Leonardo, pero en la segunda generación, solo Rubiales marcha a Italia, no constando allí la presencia de Macip, ni de Juanes. Algunos temas de Juanes, como el "Ecce Homo", fueron temas de inspiración para el maestro extremeño. En el foco andaluz, en Sevilla, Luis de Vargas visita Italia, y otros, como Pedro de Campaña y Sturmio, flamencos, se establecieron en la ciudad hispalense ${ }^{2}$.

El no aparecer documentado Luis de Morales en Badajoz, hasta el año 1539, ha dado lugar a muchas suposiciones. Carmelo Solís pensó que podría proceder de la Alta Extremadura, Plasencia, por la existencia de un pintor, Cristóbal Morales, activo allí entre 1539-1540. Sugiere, también, por el apellido Morales, que su procedencia fuera salmantina ${ }^{3}$. Tanto un lugar como otro, lo pondría en conexión con el arte "pasionario" vallisoletano.

Al parecer, Luis de Morales hace una declaración en 1584, en la que dice ser de "edad de sesenta y tres o quatro años", dándose por sentado que la fecha de su nacimiento oscilaba entre 1510 ó 1511 . Teniendo en cuenta esta fecha, el pintor debía tener treinta años, aproximadamente, cuando se establece en Badajoz. Curiosamente en este año de 1539 nace don Juan de Ribera, su futuro protector, hijo de Pere Afán de Ribera, virrey de Nápoles. Juan de Ribera fue arzobispo de Badajoz en 1562, ciudad en donde permaneció hasta su traslado a Valencia en 1568, también como arzobispo. A lo largo de su vida protegió a Morales encargándole una de las obras más significativa: La Alegoría de su muerte o Alegoría del alma, una de las primeras postrimerías de nuestra pintura.

Morales muere, mucho antes que el arzobispo Ribera, al parecer en la localidad extremeña de Valencia de Alcántara, en la que se había establecido

\footnotetext{
${ }^{1}$ Fernando Marías, El largo siglo XVI, (Madrid: Taurus, 1989), pp. 340-349; Elías Tormo, Varios estudios de Artes y Letras. Madrid, t. I, (Madrid: Centro de Estudios Históricos, 1902).

2 Diego Angulo, Ars Hispaniae, vol. XII, (Madrid: Plus Ultra, 1955), pp. 231-246; José Camón Aznar, Summa Artis, vol. XXIV, (Madrid: Espasa-Calpe, 1970), pp. 449-483; Fernando Benito Domenech, "La pintura española desde el pleno Renacimiento al Manierismo", en La Pintura española, I, (Milán: Electa, 1995), pp. 256-257; Isabel Mateo Gómez, "El Renacimiento" en Historia Universal de la Pintura, vol. 3, (Madrid: Espasa-Calpe, 1996), pp. 197-198; Marías, Largo, pp. 340-349.

${ }^{3}$ Carmelo Solís, Luis de Morales, (Badajoz: Fundación Caja de Badajoz, 1999), pp. 55-56.
} 
al final de su vida y, según testimonio de su hija, fue enterrado en la Capilla Mayor del Hospital de la Antigua Piedad 4 .

En la relación de Morales con Portugal se ha insistido, creo que demasiado, en la influencia que ejerció el pintor Fray Carlos sobre él, pero, también, pudo ejercerla Antonio de Holanda, ya que ambos pintores pudieron conocerse en la corte de Carlos V y de la emperatriz Isabel, para los que Holanda y Correa ejecutaron retratos, en el Breviario de Carlos $V$, que se encuentra en la Biblioteca de El Escorial. Miniado por Correa de Vivar, se observan, sin embargo, algunas viñetas y cenefas, que se pueden poner en relación con la pintura del portugués, especialmente en las de un libro miniado por él, sobre Las Estaciones, que se conserva en la Biblioteca Nacional de Lisboa ${ }^{5}$.

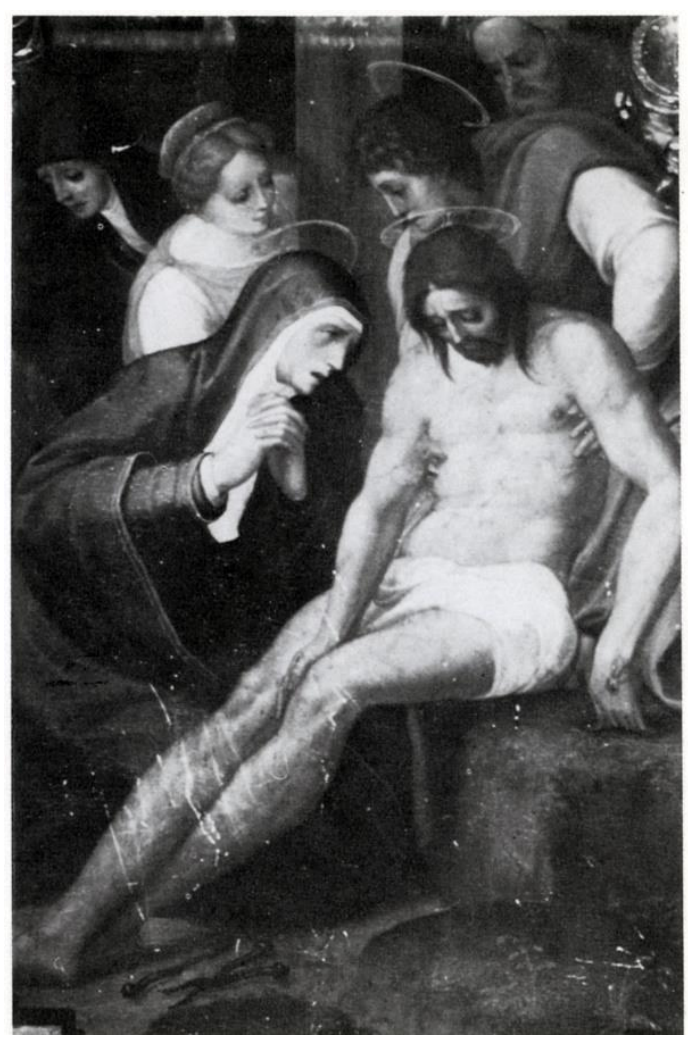

Fig. 1. Juan Correa de Vivar. La Piedad. Convento de Jerónimas de San Pablo. Toledo

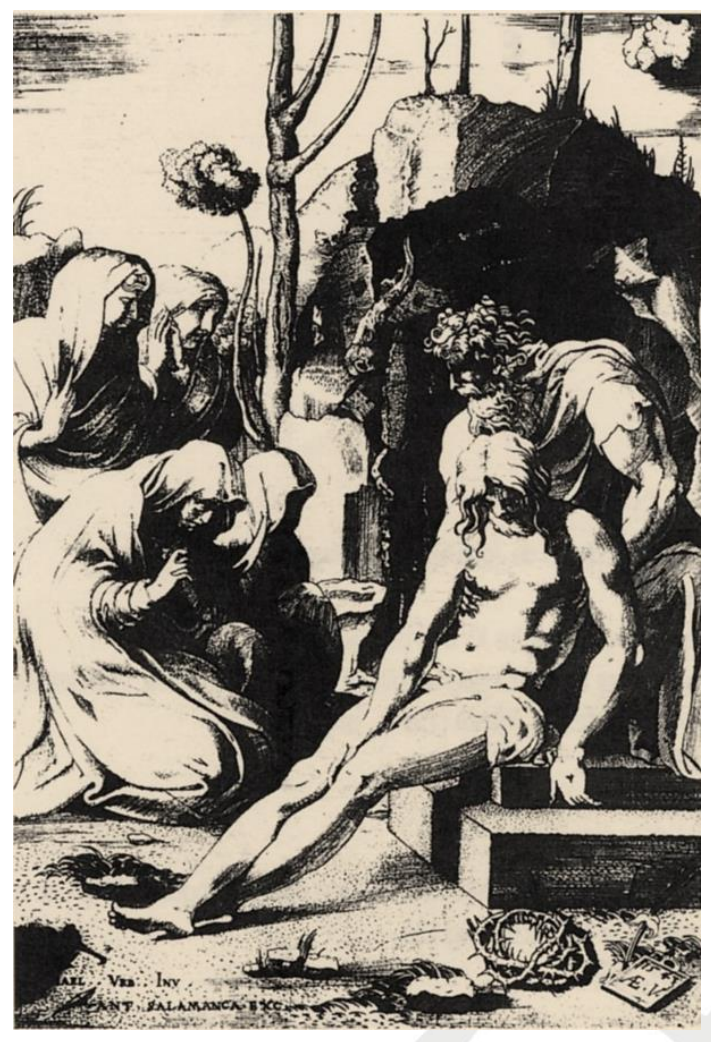

Fig. 2. Enea Vico. Entierro de Cristo, grabado

La definición de Morales como pintor "ecléctico", y de "modalidades ajenas", se puede explicar por la escasa tradición de la pintura extremeña. Sin embargo, Extremadura, geográficamente, tenía a mano a las mejores escuelas peninsulares, debiendo haber visitado Morales Valencia antes de 1546, fecha de la Virgen del pajarito, en San Agustín de Madrid, por la

\footnotetext{
${ }^{4}$ Solís, Luis de Morales, pp. 53-65; Leticia Ruiz Gómez, "Luis de Morales: divino y humano", en El Divino Morales, ed. Leticia Ruiz Gómez (Madrid, Museo Nacional de Prado, 2015) pp. 17-43.

${ }^{5}$ Isabel Mateo Gómez, "Flandes, Portugal y Toledo en la obra de Luis de Morales: Las Vírgenes gitanas o del Sombrero", Archivo Español de Arte, vol. LXXX, no 317, (2007) pp. 7-24. (Agradezco a Ma Teresa Desterro el haber podido conocer las miniaturas de Antonio de Holanda); Juan Antonio Gaya Nuño, Luis de Morales, (Madrid: C.S.I.C., 1961), p. 31.
} 
similitud compositiva entre ella y el grupo de la Virgen con el Niño, que pintó Llanos, en el Descanso en la Huída a Egipto, para el retablo de la catedral de Valencia. Su visita y conocimiento de la escuela valenciana fue, pues, anterior a la llegada a la ciudad del arzobispo Ribera.

Gaya Nuño sintetizó todas las definiciones que se habían dado sobre el pintor en su Luis de Morales, de 1961, pero hay una que quisiera subrayar y que afecta a la mayoría de los pintores de aquel momento. La frase es de Francisco Gregorio de Sales, en 1773, quien considera el estilo de Morales como de "modesto y peregrino", interpretándolo Gaya como un referente al "manierismo casero, domesticado, pero interesante", lo que nosotros llamaríamos ahora "no conceptual".

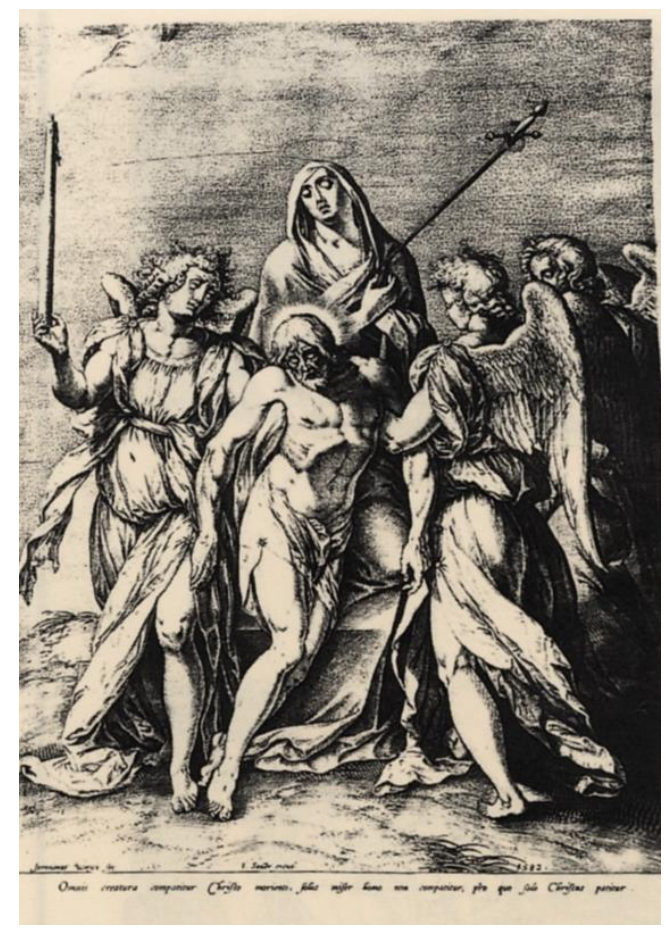

Fig. 3. Hieronymus Wierix. Cristo sostenido por ángeles, grabado

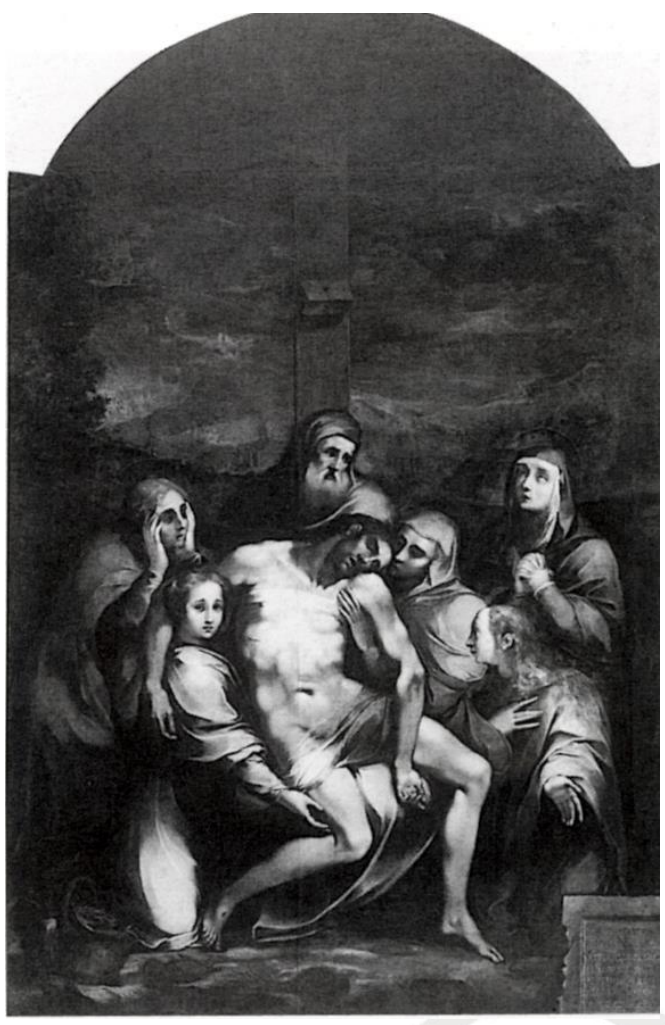

Fig. 4. Blas de Prado. Piedad. Catedral de Valencia

En su "peregrinaje" por las diversas escuelas, Morales encontró a Alonso Berruguete, llegado de Italia, quien le influyó en formas y claroscuro y, cercano a este, al Maestro Benito, con su manierismo estilizado y color ensombrecido. En Valladolid, no pudo permanecer ajeno a la escultura de Gregorio Fernández, de Juan de Juni y del propio Berruguete. En Toledo, Machuca ofrece los mismos parámetros italianos en cuanto al claroscuro y colorido manierista y Sevilla, se incorpora a estas influencias italianas, pero con algún sentimiento nórdico, especialmente en el caso de Sturmio, e 
italiano en Luis de Vargas. El tan traído y llevado "leonardismo", lo representan los Hernandos en Valencia, pero con más viveza en color ${ }^{6}$.

Pérez Sánchez estableció un paralelismo sobre lo que significó Juan de Juanes en Valencia, Juan Correa de Vivar en Toledo, Morales en Extremadura y Luis de Vargas en Sevilla, aceptando que algunos se habían incorporado al Renacimiento, "de segunda mano"7.

La interrelación de Morales con Correa de Vivar y Machuca, ya se ha estudiado. De Correa de Vivar dijo Elías Tormo, "que no fue escasa su influencia en estas tierras de España". Entre Correa y Morales existen, por supuesto, diferencias, entre ellas que el primero es un gran pintor de retablos, y el segundo, no, al preferir la cercanía devocional del tema. Hay que recordar

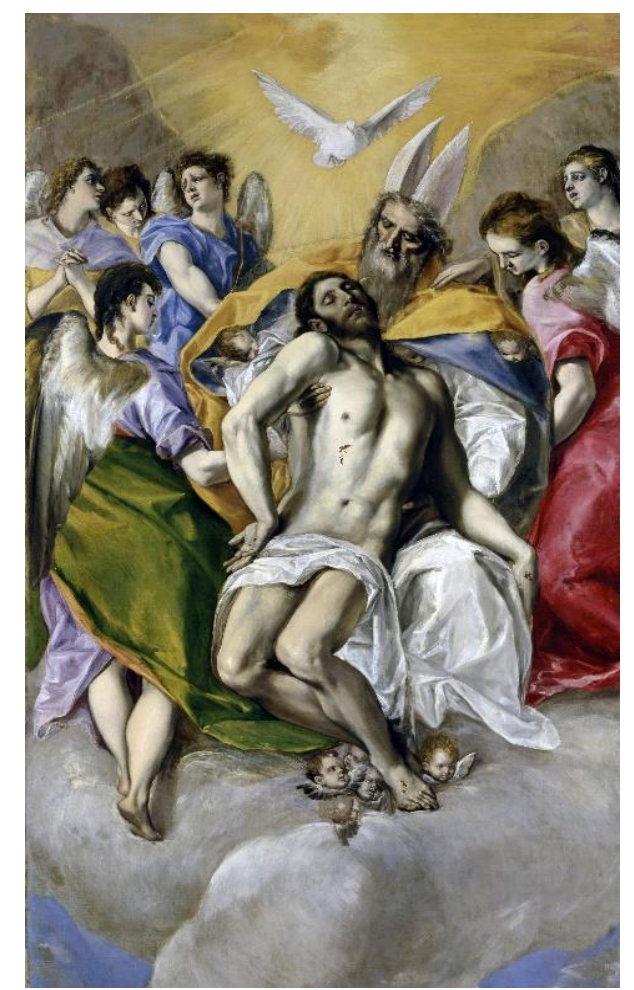

Fig. 5. El Greco. Trinidad, Museo del Prado, Madrid. Foto, Museo del Prado®

la influencia en Morales del retablo de Correa, pintado para la iglesia de Herrera del Duque (Badajoz), entre 1548-1550, y la de Cornelio Cyaneus en el retablo de Villar del Pedroso (Cáceres), en $1561^{8}$. Cuando Pérez Sánchez

\footnotetext{
${ }^{6}$ Gonzalo Redín Michaus, Pedro Rubiales, Gaspar Becerra y los pintores españoles en Roma. 1527-1600, (Madrid: C.S.I.C., 2007), pp. 255-311; Fernando Benito Domenech, Pinturas y pintores del Real Colegio del Corpus Christie, (Valencia: Generalitat, 1980), pp. 5-7; Marías, Largo, pp. 340-349; Joan de Joanes. Un maestro del Renacimiento, ed. Fernando Benito Domenech, (Madrid: Fundación Santander Central Hispano, 2000), pp. 15-72; Los Hernando: pintores hispanos del entorno de Leonardo, ed. Fernando Benito Domenech (Valencia: Museo de Bellas Artes, 1998), pp. 21-59.

7 Alfonso Emilio Pérez Sánchez, "Juan de Juanes en su centenario", Archivo Español de Arte, vol. I, (1979), pp. 5-16.

8 Tormo, Varios, 1902; Isabel Mateo Gómez, "El pintor Cornelio Cyaneus o Caenus: revisión del contrato del retablo de Villar del Pedroso y aportación al catálogo de su obra e influencias artísticas" en Creer y
} 
define a Morales y a su obra dice lo siguiente: "...artista complejo y personal, que funde los modelos italianos, técnica preciosista flamenca y un cierto apasionado expresionismo piadoso de fondo manierista... la imitación [de sus propias obras] se debe, entre otras cosas, a que la imagen religiosa cumplía unas funciones efectivas y didácticas observándose un proceso de inflación" que alcanzó "un claro fenómeno de reiteración"9.

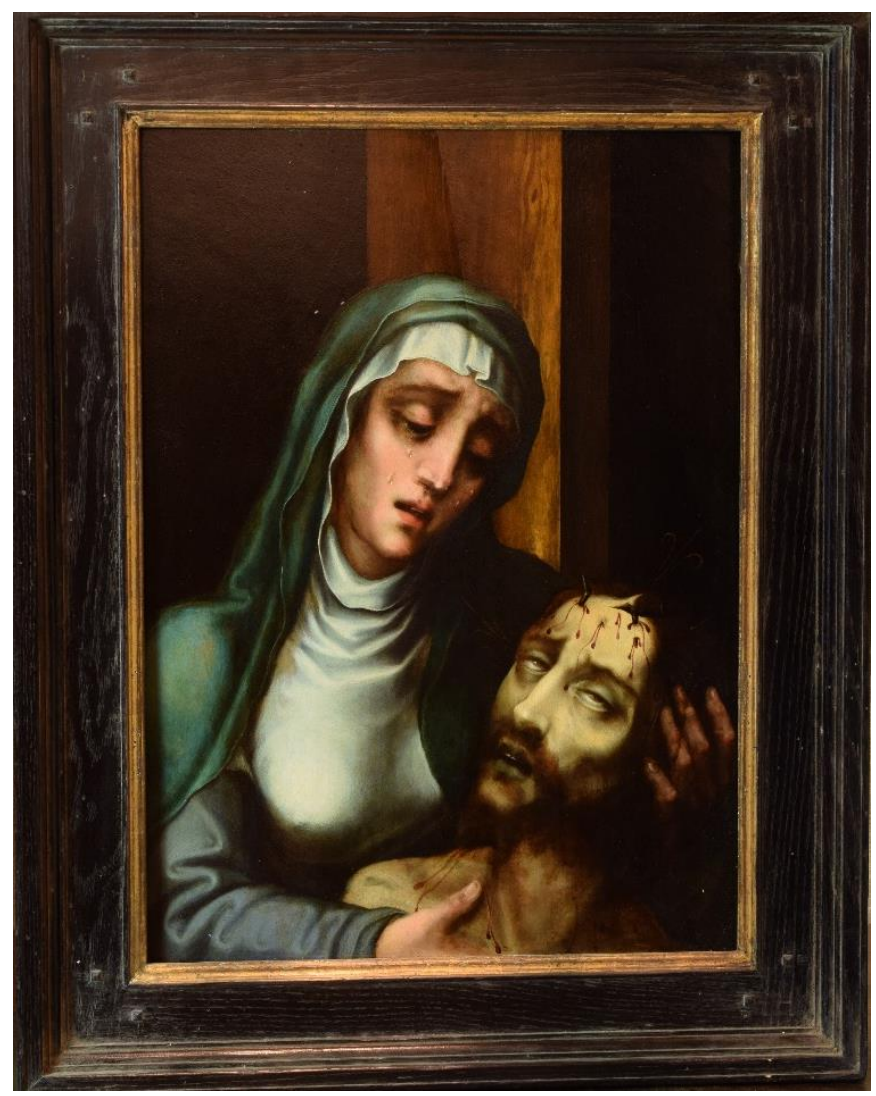

Fig. 6. Luis de Morales, Piedad, colección privada, Madrid

Referente a la relación de Morales con otras escuelas, ya hemos hecho referencia a la Virgen del pajarito, con Llanos; y como los Ecce Homo, de Juan de Juanes están presentes en los suyos. Ya se ha señalado en otro trabajo la importante conexión con Correa de Vivar, quien influye en el extremeño en color, claroscuro y sentimiento piadoso. Puede servir de ejemplo La Piedad o El Entierro de Cristo, (Fig. 1) del retablo del coro de las Jerónimas de Toledo que, a su vez, está inspirado en una estampa de Enea Vico, según Rafael, fechada en 1543 (Fig. 2). La importancia de la estampa, en general, es bien conocida. Morales utilizó, como otros pintores toledanos,

entender: Homenaje a Ramón Gonzálvez Ruiz, vol. 2., (Real Academia de Bellas Artes y Ciencias Históricas, Toledo, 2014), pp. 825-840; Isabel Mateo Gómez, "Nuevos campos abiertos a la investigación a partir de algunas exposiciones dedicadas a la obra de El Greco", Arbor, no 776, (nov-dic. 2015), p. a279, fig. 13

9 Panorama de la pintura española desde los Reyes Católicos a Goya, ed. Alfonso Emilio Pérez Sánchez (Buenos Aires, Palacio del Concejo Deliberante, 1980), p. 20, lám. XI. 
la de Hieronymus Wierix, Cristo sostenido por ángeles y la Virgen, (Fig. 3) en varias Piedades, en las que el cuerpo de Cristo cae en vertical sobre el de María. También influye en la Piedad de Blas de Prado de la catedral de Valencia, (Fig. 4) y en la Trinidad, de El Greco, del museo de El Prado (Fig. 5). La similitud escénica y compositiva entre el Pentecostés, de Rubiales, en la capilla Sumaria de Nápoles, y la de Correa de Vivar en la catedral de Teruel,

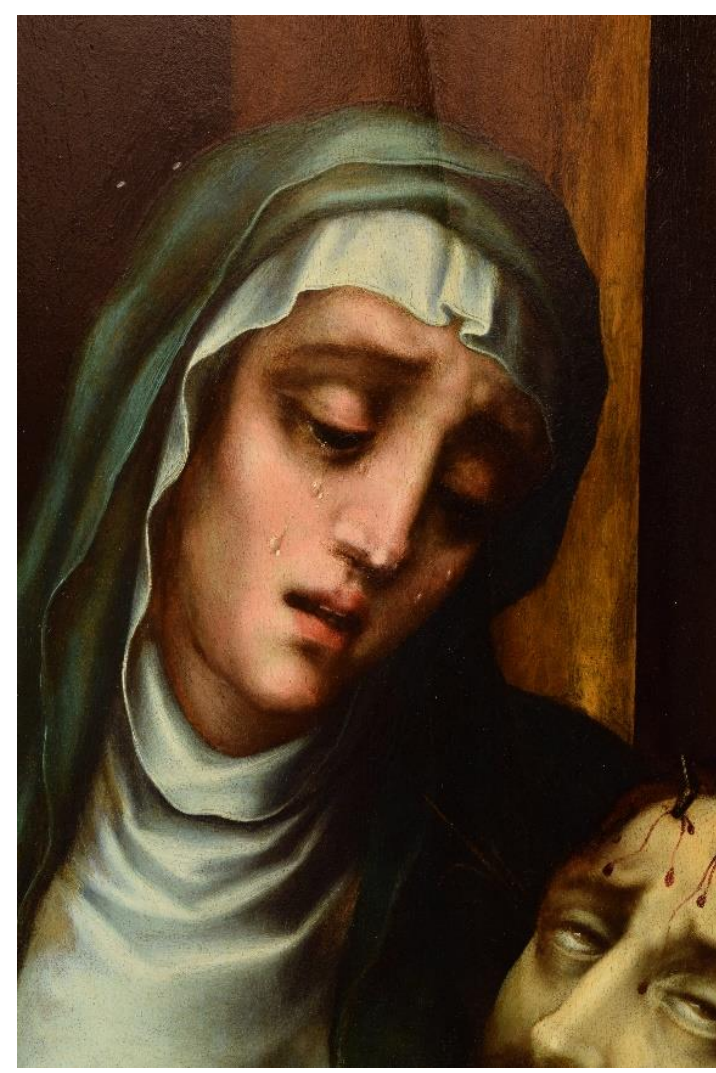

Fig. 7. Luis de Morales. Piedad. Detalle. Colección privada. Madrid

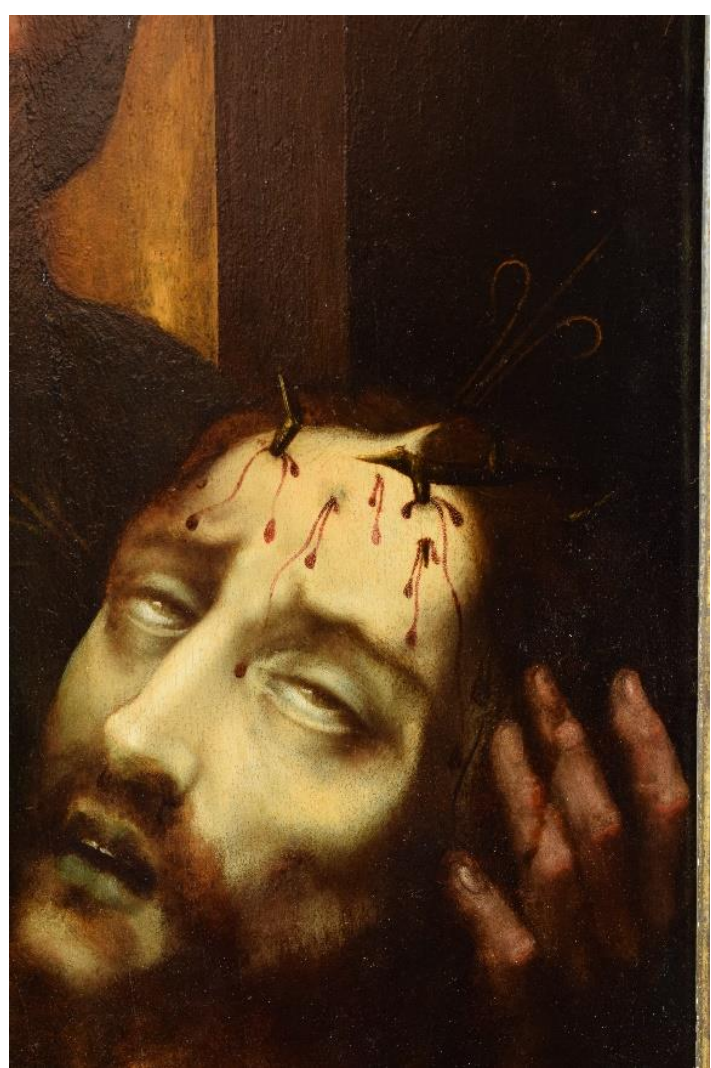

Fig. 8. Luis de Morales. Piedad. Detalle. Colección privada. Madrid

hace presumir la existencia también de una estampa ${ }^{10}$.

Rogelio Buendía, en El Prado básico, al tratar sobre el Descendimiento de Van der Weyden, alude al artículo de Von Simson, sobre los criterios teológicos, relacionados con la "Compasio", el dolor compartido de María con su Hijo, que deriva de San Bernardo de Claraval, y el de la "Co-redemptio", que pone en relación con el "Stabat-Mater". Otra observación de Buendía es sobre el "oro" del fondo, interpretándolo como un medio para conseguir un sentido intemporal a la escena. Esta consideración nos hace pensar si los "oscuros-neutros" de los fondos de Morales, Correa, Campaña, Machuca, etc.,

${ }^{10}$ Real colección de estampas de San Lorenzo de El Escorial, ed. Jesús María González de Zárate, vol. IX, (Vitoria-Gasteiz: Ephialte, 1994), pp. 130 y 199; Redín Michaus, Pedro Rubiales, p. 105. 
pudieran querer expresar este sentido trascendental, no solamente una característica manierista ${ }^{11}$.

Enlazando con este párrafo de Buendía sobre la Piedad de Van der Weyden, damos a conocer una nueva versión inédita del tema, donde el "apasionado expresionismo piadoso" de Morales, se convierte en casi una desgarradora "postrimería". La tabla, que se halla en colección privada madrileña, mide 59,9 × 40, $9 \mathrm{~cm}$., y creo que puede fecharse en la última etapa del pintor, entre 1565 y 1570. La escena, como es costumbre en Morales en los temas pasionarios, se desarrolla sobre fondo oscuro en el que destaca la verticalidad del madero de la Cruz, pudiendo apreciarse las calidades de la madera. Sobre este brazo de la cruz aparecen, superpuestas, en algo menos de medio cuerpo, las figuras de la Virgen abrazando a Cristo muerto. El manto, que cubre a la Virgen, ocupa un gran espacio en la composición, sirviendo de cobijo al Hijo, en el que destaca, especialmente, la herida de la cabeza, después de haber sido expoliado de la corona de espinas. El manto es de un color azul verdoso, la túnica de un morado-rosado, y la toca blanca, se frunce sobre la frente y se prolonga hasta algo más abajo del pecho, marcándolo. El rostro de la Virgen es de profundo dolor y por el corren sutiles lágrimas, uniéndose en su expresión dolor, piedad y ternura al acercarse a la cabeza de Cristo, situación que Camón describió como "que parecía quererle entibiar con su aliento"12. El pintor ha centrado toda su atención en la realista cabeza de Cristo: el rostro de tez pálida, los labios entreabiertos y amoratados, los ojos con la mirada "vacua" de un cadáver. Pero, donde la crudeza se muestra más desgarradora, es en las cuatro espinas restantes del expolio, que han quedado clavadas hasta el cráneo, levantándole la piel (Figs. 6-8). En otras Piedades de Morales, pintadas con idéntico tema - la del Museo de Bellas Artes de Bilbao y la del Museo del Prado - el efecto no es tan aterrador. Esta singular tabla se halla en buen estado de conservación. Cuando la vi en el 2010 en Derek John Ltd., de Londres, sólo existían algunas partes afectadas, pero no esenciales, advirtiéndose las "potencias" sobre la cabeza de Cristo.

Angulo señaló que la Piedad fue uno de los temas predilectos del pintor, repitiéndola con algunas variantes, bien como en el ejemplo de la Academia de San Fernando y el de la catedral de Badajoz - de cuerpo entero - o como el que estudiamos de busto, que fue el más repetido, por la exigente clientela que pedía una tabla "cercana" para su devoción particular. Los ejemplos de las Teresas de Sevilla, del Palacio Arzobispal de Madrid, y la de la Fundación Villar Mir, son buena muestra de ello ${ }^{13}$.

Todos los estudiosos de Morales coinciden en observar la influencia de los Primitivos Flamencos sobre su obra, especialmente la de Memling, Van der

\footnotetext{
11 José Rogelio Buendía, El Prado básico, (Madrid: Sílex, 1973), p. 9, lám. XI

12 Camón Aznar, Summa, vol. XXIV, p. 474.

${ }^{13}$ Angulo Iñiguez, Ars Hispaniae, XII, pp. 240-241.
} 
Weyden y Metsys, los del Prado y el de la Pinacoteca de Múnich son ejemplos muy cercanos.

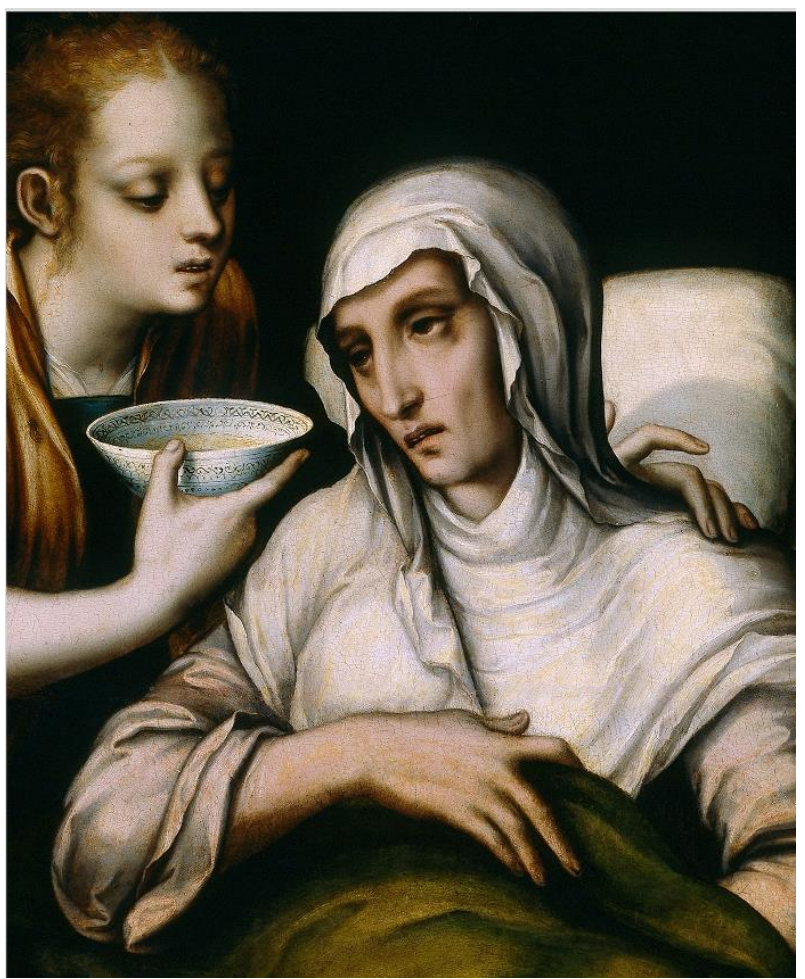

Fig. 9. Luis de Morales, Nacimiento de la Virgen (detalle), Museo del Prado, Madrid. Foto, Museo del Prado@

En ninguna composición de los Primitivos Flamencos, ni en ninguna de otra escuela europea, incluida España, aparecen las "espinas clavadas en el cráneo, sin la corona"; solo en una Piedad de Rubens, citada por Réau, aparece la Virgen cerrándole los ojos a Cristo muerto y con una espina en la mano ${ }^{14}$. ¿Por qué este tema solo aparece en Morales? Tres autores se han dedicado a la literatura espiritual de la época de Morales y de El Greco: David Davis, Alfonso Rodríguez Gutiérrez de Ceballos y Fernando Marías ${ }^{15}$. Los tres coinciden en resaltar la importancia de la literatura mística del momento, los presupuestos de Trento, y ciertas influencias erasmistas. Rodríguez G. de Ceballos y Marías, a propósito del ambiente que vivió Morales en Badajoz, difieren en que el primero acentúa el "provincialismo" de la ciudad extremeña, mientras que Marías subraya el ambiente intelectual de los mecenas y clientela del pintor, especialmente la protección del arzobispo Juan de Ribera, tanto en Badajoz como en Valencia, nombrando a Morales su pintor de cámara. Las dos grandes figuras que con sus escritos cubrieron la mística en aquellos años fueron Juan de Ávila y Fray Luis de Granada, amigos de

\footnotetext{
14 Louis Réau, Iconographie de l'Art Chrétien. Iconographie de la Bible, t. 1, vol. 2, (Paris: Presses Universitaires de France, 1957), p. 519. La iconografía puede deberse a la formación del pintor con los jesuitas, ya que algunos de ellos conocían a los místicos "españoles".

${ }^{15}$ David Davies, "El Greco and the Spiritual Reform Movements in Spain", en Studies in the History or Art, vol. 13, (1984), pp. 57-75; Alfonso Rodríguez Gutiérrez de Ceballos, "El mundo espiritual del pintor Luis de Morales", Goya, no 196, (1987), pp. 194-203; Marías, Largo, pp. 340-349.
} 
Ribera y en contacto, sin duda, con el pintor. Tanto Ceballos como Marías, reproducen textos inspiradores de la obra "pasionaria" de Morales, pero de manera general. Así Juan de Ávila escribe: "la Pasión se ha de imitar lo primero con compasión y sentimiento aún de la parte sensitiva y con lágrimas", y fray Luis de Granada: "Abrázale la Madre con el cuerpo desplazado de su Hijo, apriétalo fuertemente en sus pechos, para solo esto le quedaban fuerzas, mete su cara entre las espinas [corona] de la sagrada cabeza". Este pasaje, Guè Trapier y Rodríguez G. de Ceballos, lo aplican a la Piedad de la Academia de San Fernando (inv. no 612). Fernando Marías, aunque tampoco piense en las Piedades de Morales, en las que Cristo tiene las espinas clavadas en el cráneo, después de quitarle la corona, se muestra más explícito en la reproducción del texto de Fray Luis de Granada, ofreciendo otras consideraciones. Así, cuando escribe sobre la tabla de Morales, La alegoría de la muerte de Juan de Ribera, comenta el papel trascendental que tiene ésta en nuestra pintura, al convertirse en la primera de las "postrimerías", género al que pensamos pertenece la Piedad de la colección madrileña, que damos a conocer, por su realismo, y porque nos evoca ciertas composiciones macabras de nuestra pintura barroca, especialmente de Valdés Leal. Marías, al reproducir el texto de fray Luis de Granada, Libro de la Oración y meditación, del mismo modo que se había referido a las "postrimerías" en la Guía, del citado místico, dice: "mira lo que sentirías, si en una parte tan sensible como la cabeza, te hincasen muchas y muy agudas espinas que penetrasen hasta los huesos... Mis pecados son Señor, las espinas que te punzan... yo soy la causa de tu dolor". Morales en la Piedad de la colección madrileña, superó con su realismo el texto citado. Marías considera que estos textos místicos eran "un método imaginativo de meditación devocional", como lo fueron por estos mismos años los Ejercicios Espirituales de San Ignacio de Loyola. A ellos, tal vez habría que sumar el de fray Alonso de Cabrera (1549?-1598), Consideraciones sobre todos los Evangelios de la Cuaresma, seguidor de fray Luis de Granada y predicador de Felipe II.

Estilísticamente, el modelo de la Virgen de la Piedad madrileña se asemeja mucho al de la Santa Ana del Nacimiento de la Virgen, (fig. 9) del Museo del Prado (inv. no P07859), fechado en 1565. Según la ficha del catálogo de la reciente exposición en el Prado ${ }^{16}$, el Nacimiento de la Virgen pudo haber formado parte, junto a la Presentación en el templo y a la Visitación, ambas en el Museo Schloss Fasanerie, del retablo dedicado a la Vida de la Virgen, que fue encargado por Fray Antonio Bravo de Xerez (†1562) para su capilla funeraria en un convento de San Benito de Alcántara (Cáceres). Desaparecido y dispersado el retablo, probablemente en la desamortización o cuando las guerras napoleónicas, sugerimos que, tal vez, esta Piedad pudo haber formado parte de él en el remate del retablo, coincidiendo el tema como un episodio más de la Vida de la Virgen, y muy de acuerdo con el sentido funerario de la capilla.

16 E. Cenalmor Bruquetas, "El nacimiento de la Virgen, la Visitación y la Presentación en el templo" en EI Divino Morales, Cat. Exp., 2015, pp. 60-64. 
No quisiéramos cerrar este apartado, sin citar dos Piedades de Juan Correa de Vivar. Una muy próxima a Morales, del retablo de Calzada de Calatrava (Ciudad Real), y un detalle de otra, en colección privada madrileña, ambas de la última etapa del pintor toledano.

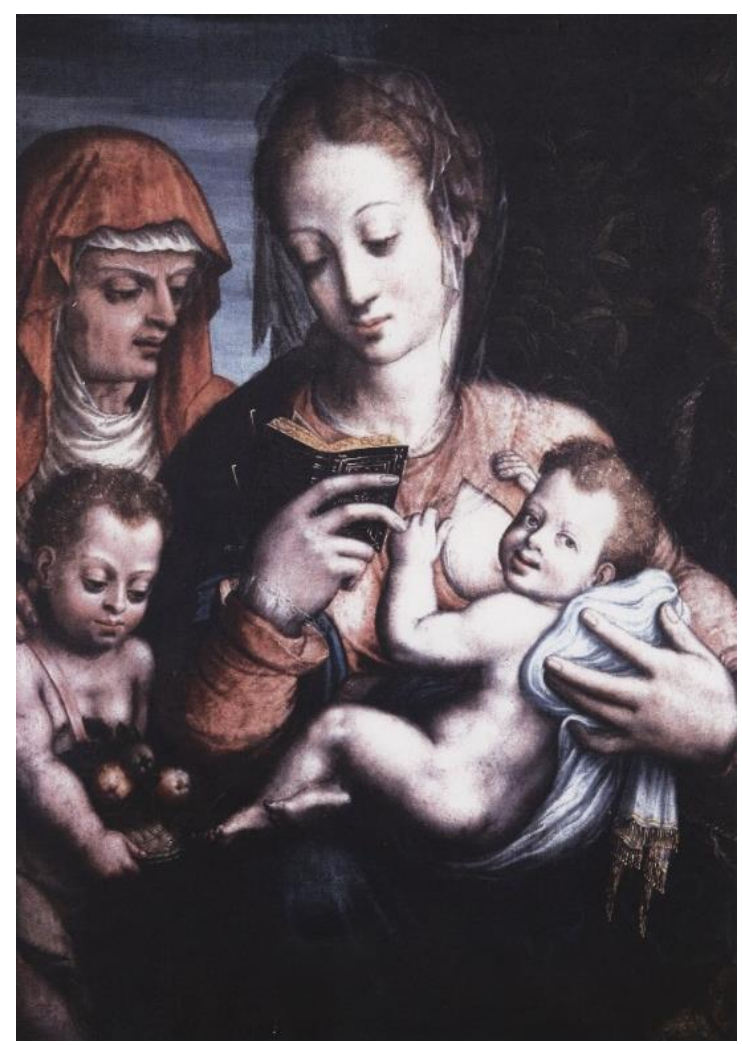

Fig. 10. Luis de Morales (atribuido), Virgen de la Leche con Santa Ana o Santa Isabel y San Juanito, colección privada

La siguiente tabla que damos a conocer de Luis de Morales se halla alejada de la imagen tradicional de la obra del pintor. Se trata de una Virgen de la Leche con Santa Ana o Santa Isabel y San Juanito en colección privada madrileña. (Fig. 10) En esta tabla, el modelo de la Virgen y el sentido del color aparecen en otra obra de Morales, la Madonna della Puritá en la Basílica de San Paolo Maggiore de Nápoles, fechada por Leticia Ruiz, acertadamente, hacia 1550 (Fig. 11), y que Gaya Nuño fechó bastantes años después ${ }^{17}$.

El fondo de la pintura de la Virgen de la Leche de colección privada no es frecuente, se divide en una parte ajardinada a la izquierda, y un celaje a la derecha. Este fondo ajardinado, curiosamente, lo hemos localizado en una Virgen con el Niño de Geertgen tot Sint-Jans, en el Rijksmuseum de Ámsterdam. En la Virgen madrileña de Morales, además de ser más rica en color, se observa, en algunos detalles, cierto sentido decorativo poco usual en el pintor, si exceptuamos el hacha que parte la cabeza de San Pedro de Verona en la colección Masaveu. El empleo del oro, en el libro y en los flecos del pañal, algo arcaico, evocaría, tal vez, algunos ejemplos de la escuela

17 Ruiz Gómez, "Luis de Morales: divino", p. 29; Gaya Nuño, Luis de Morales, p. 41. 
sevillana. El cesto de frutas que Ileva san Juanito es idéntico al que lleva la joven en el Nacimiento de la Virgen del Museo del Prado, pintado por Morales. Las naturalezas muertas, presentes en la escuela toledana desde Juan Correa de Vivar a Blas de Prado y primeras obras de Sánchez Cotán, están influidas, a veces, por grabados de Saedeler. Los modelos de los niños los hallamos en

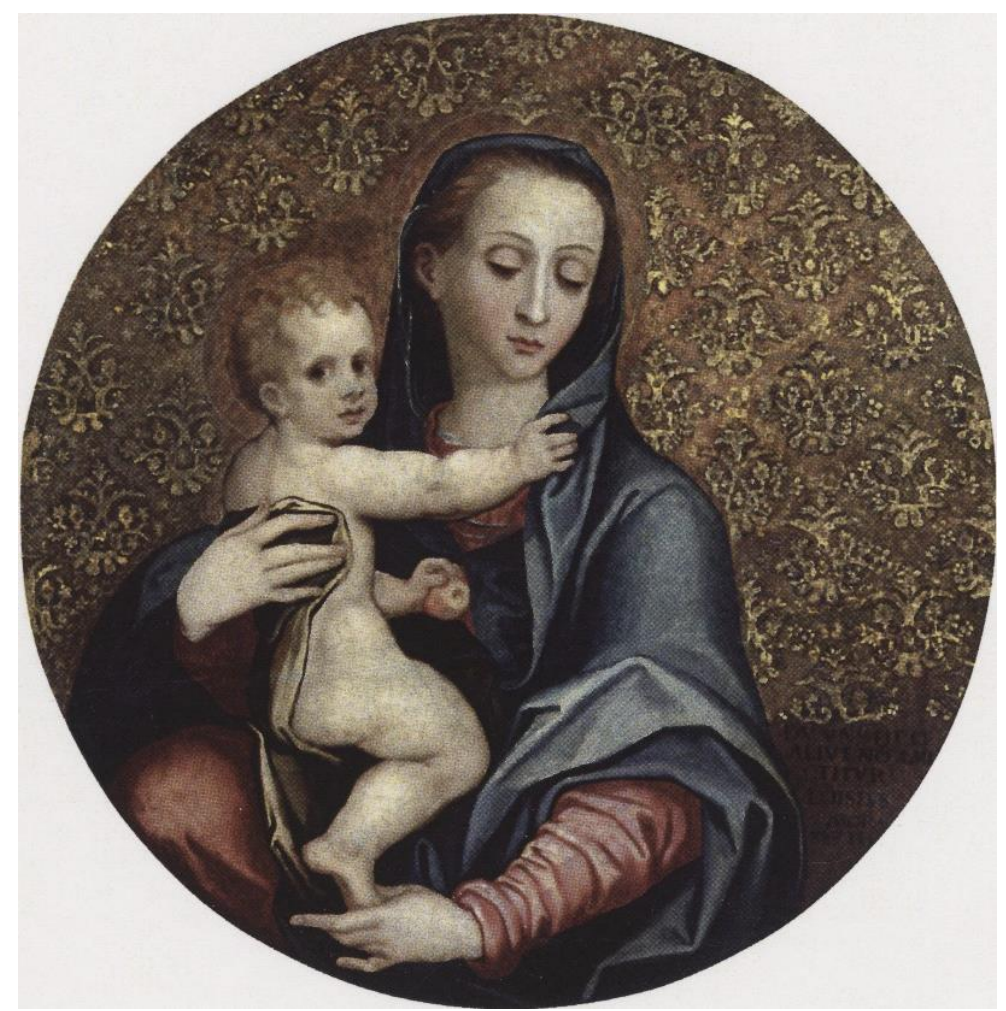

Fig. 11. Luis de Morales. Madonna della Puritá. Basílica de San Paolo Maggiore. Nápoles

la Virgen con el Niño de Lisboa, y en la tabla de Valencia de Alcántara, en la que el Niño escribe en un libro, obras importantes de Morales.

El modelo de la Virgen, el porte de la cabeza, el tratamiento del cabello, la sutileza de la camisilla y el velo que cubre la cabeza, al igual que el color, la pone en relación, como hemos dicho con la Madonna della Puritá. En ambas composiciones el Niño vuelve la cabeza hacia el espectador, y la manzana es protagonista. También hallamos analogías con las pinturas de Luis de Vargas y Sturmio, existiendo de este último una Sagrada Familia con San Joaquín y Santa Ana en Sanlúcar de Barrameda, en la que el bodegón juega un importante papel.

La presencia en Nápoles de dos obras de Morales, la Madonna della Puritá y la Última Cena, según Carmelo Solís, pudo deberse al Virrey Afán de Ribera, quien, al parecer, encargó a su hijo, siendo todavía arzobispo de Badajoz, dos tablas de Morales con el tema de la Virgen. Los Afán de Ribera estuvieron muy vinculados a Toledo y a sus pintores, concretamente con Blas de Prado 
e Isaac de Helle, flamenco ya citado, establecido en la ciudad imperial en $1562^{18}$.

El "idilio maternal" del tema deriva de la escuela flamenca, siendo Rafael divulgador del tema y nuestra escuela valenciana muy pródiga en su escenificación, especialmente en Juan de Juanes.

Una iconografía muy similar a la Sagrada Familia, que hoy damos a conocer, la representa El Greco en 1585, hallándose en el museo de Santa Cruz de Toledo.

Morales fue un pintor enamorado de la técnica, composición e iconografía flamenca, pero supo revestir estas preferencias con las maneras y el color, que en cada etapa exigía el momento de su longeva vida, y el gusto del comitente que le encargaba la obra.

${ }^{18}$ Solís, Luis de Morales, p. 287; Isabel Mateo Gómez y Amelia López-Yarto Elizalde, La pintura toledana de la segunda mitad del siglo XVI, (Madrid: C.S.I.C., 2003), pp. 223 y 263. 
Bibliografía:

Angulo 1955: Diego Angulo, Ars Hispaniae, vol. XII (Madrid: Plus Ultra, 1955).

Benito Domenech 1980: Fernando Benito Domenech, Pinturas y pintores del Real Colegio del Corpus Christie, (Valencia: Generalitat, 1980).

Benito Domenech 1995: Fernando Benito Domenech, "La Pintura española desde el pleno Renacimiento al Manierismo", en La Pintura Española, vol. I, (Milán: Electa, 1995), pp. 245-290.

Buendía 1973: José Rogelio Buendía, El Prado básico, (Madrid: Sílex, 1973).

Buenos Aires 1980: Panorama de la pintura española desde los Reyes Católicos a Goya, ed. Alfonso Emilio Pérez Sánchez (Buenos Aires, Palacio del Concejo Deliberante, 1980).

Camón Aznar 1970: José Camón Aznar, Summa Artis, vol. XXIV, (Madrid: Espasa-Calpe, 1970).

Davies 1984: David Davies, "El Greco and the Spiritual Reform Movements in Spain", Studies in the History of Art, vol. 13, (1984) pp. 57-75

Gaya Nuño 1961: Juan Antonio Gaya Nuño, Luis de Morales, (Madrid: C.S.I.C., 1961).

Madrid 2000: Joan de Joanes. Un maestro del Renacimiento, ed. Fernando Benito Domenech, (Madrid, Fundación Santander Central Hispano, 2000).

Madrid 2015: El Divino Morales, ed. Leticia Ruiz Gómez (Madrid, Museo Nacional de Prado, 2015).

Marías 1989: Fernando Marías, El largo siglo XVI, (Madrid: Taurus, 1989).

Mateo Gómez 1996: Isabel Mateo Gómez "El Renacimiento", en Historia Universal de la Pintura, vol. 3, (Madrid: Espasa-Calpe, 1996).

Mateo Gómez 2007: Isabel Mateo Gómez, "Flandes, Portugal y Toledo en la obra de Luis de Morales: Las Vírgenes gitanas o del Sombrero", Archivo Español de Arte, vol. LXXX, no 317, (2007), pp. 7-24

Mateo Gómez 2014: Isabel Mateo Gómez, "El pintor Cornelio Cyaneus o Caenus: revisión del contrato del retablo de Villar del Pedroso y aportación al catálogo de su obra e influencias artísticas" en Creer y entender-Homenaje a Ramón Gonzálvez Ruiz, vol. 2., (Real Academia de Bellas Artes y Ciencias Históricas, Toledo, 2014), pp. 825-840.

Mateo Gómez 2015: Isabel Mateo Gómez, "Nuevos campos abiertos a la investigación a partir de algunas exposiciones dedicadas a la obra de El Greco", Arbor, no 776 (nov-dic. 2015), a.279 
Mateo Gómez y López-Yarto Elizalde 2003: Isabel Mateo Gómez y Amelia López-Yarto Elizalde, La Pintura toledana de la segunda mitad del siglo XVI, (Madrid: C.S.I.C., 2003).

Pérez Sánchez 1979: Alfonso Emilio Pérez Sánchez, "Juan de Juanes en su centenario", Archivo de Arte Valenciano, vol. I, (1979), pp. 5-16

Real Colección de Estampas de San Lorenzo de El Escorial, ed. Jesús Ma González de Zárate, vol. IX (Vitoria: Ephialte, 1995).

Réau 1955-1959: Louis Réau, Iconographie de l'Art Chrétien. Iconographie de la Bible, t. 1, vol. 1-2, t. 2, vol. 3-5., (Paris: Presses Universitaires de France, 1955-1959)

Redín Michaus 2007: Gonzalo Redín Michaus, Pedro Rubiales, Gaspar Becerra y los pintores españoles en Roma, 1527-1600, (Madrid: C.S.I.C., 2007).

Rodríguez Gutiérrez de Ceballos 1996: Alfonso Rodríguez Gutiérrez de Ceballos, "El Mundo espiritual del pintor Luis de Morales", Goya, no 196, (1997), pp. 194-203.

Solís 1999: Carmelo Solís, Luis de Morales, (Badajoz: Fundación Caja de Badajoz, 1999).

Tormo 1902: Elías Tormo, Varios estudios de Artes y Letras, t. I (Madrid: Centro de Estudios Históricos, 1902)

Valencia 1998: Los Hernando: pintores hispanos del entorno de Leonardo, ed. Fernando Benito Domenech (Valencia, Museo de Bellas Artes, 1998). 